\title{
Supplier Knowledge Management For Supplier Development
}

Ali Mollahosseini, Shahid Bahonar University, Iran

Mehdi Barkhordar, Shahid Bahonar University, Iran

\begin{abstract}
Due to rapid and unpredictable changes in the business environment, nowadays organizations have to be innovative to survive in the marketplace. Many firms have applied knowledge management to reduce production costs, innovate new products, and attract customers and suppliers. Hence, firm's management has to maintain competitive advantage by providing inputs through a dynamic supplier network. Supplier development programs help businesses to identify collaborative suppliers. Therefore, Supplier Knowledge Management plays an important role for the firms to create switching costs and raise barriers to entry. In this paper, initially we define knowledge management, and supplier knowledge management, and then a conceptual framework is presented to enhance supplier performance. We will demonstrate how companies can benefit by adopting supplier knowledge management.
\end{abstract}

Keywords: Knowledge; Knowledge Management; Supplier Development

\section{INTRODUCTION}

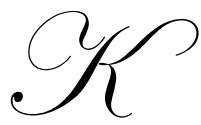

nowledge management is to promote business success through a formal, structured initiative to improve the use of knowledge in an organization, in which an effective organizational memory information system plays an increasingly important role. Unlike the past, the performance of an enterprise now depends much on the performance and relationship of its customer-suppliers in the value chain. Good customer-supplier relationships are important for an organization to respond to dynamic and unpredictable changes. Their work describes a knowledge-based supplier selection and evaluation system, which is a case-based reasoning decision support system for outsourcing operations. By using the system, the cumulative performance of suppliers is constantly updated automatically according to past practice. This means that the knowledge of suppliers can be retained, categorized, retrieved and managed effectively (Choy \& Lee \& Lau and Choy, 2005).

Modi and Mabert (2007) note that Suppliers represent a critical resource to a firm Providing both direct and indirect materials and services, Which are inputs to the organization's product offerings. The quality and cost of a product or service offered in the Market is a function, not only of the capabilities of the firm, but also of the network of suppliers who provide inputs to the enterprise. When an organization finds its suppliers lacking in performance it can help suppliers to develop their capabilities. There is strong evidence that organizations today are increasingly implementing supplier development programs to improve supplier development: Improving supplier performance.

Tseng(2008) notes that due to the rapid development of knowledge and information technology (IT), business environments have become much more complicated. In order to cope with ensuing complications, enterprises ought to incessantly innovate; otherwise, it will be very difficult for them to survive in the marketplace. Hence, many enterprises have applied IT in order to cut production costs, introduce innovations in products and services, promote growth, develop alliances, lock in customers and suppliers, and create switching costs and raise barriers to entry. In other words, IT can help a firm aiming to gain a competitive advantage. In addition, many studies have argued that business value comes mainly from intangible assets, such as knowledge. Thus, knowledge workers will be able to replace clerical workers as the new mainstream of manpower resources, a field in which the development of IT is the major force for change in knowledge management system (KMS). 


\section{KNOWLEDGE}

Knowledge refers to an observer's distinction of "objects" through which he brings forth from the background of experience a coherent and self-consistent set of coordinated actions. Through the process of distinction, individual pieces of data and information become connected with on another in a framework of relations. Knowledge then is contained in the overall organizational pattern of the network and not in any of the components. Knowledge is more than information. Information is data organized into meaningful patterns. Information is transformed into knowledge when a person reads, understands, interprets, and applies the information to a specific work function. Knowledge becomes visible when experienced persons put into practice lessons learned over time (Lee and Yang, 2000).

When information is analyzed and processed it becomes knowledge. Knowledge is identifying unrecognized patterns, latent procedures, and data exceptions. Knowledge is creating a mental model or pattern of a protocol that can be used in a specific field with high reliability. Also knowledge can be defined as a complicated process that for making valuable judgments according to experiences needs human. Due to these experiences and past perceptions, a person may have defined and formulated rules, which can be used for the same situations with high reliability.

Knowledge in organization means whatever people know about customers, products, processes, mistakes, and successes. Knowledge of organization could be placed in minds of people, groups, and its departments, and is considered as the main part of executive processes and regulations and rules ( HajiAzizi, N., DokhtEsmati, M.,Moradi,S., 2009).

The concept of knowledge is widely discussed in various disciplines, but the definition varies. Knowledge is understood primarily as a resource, either as an input resource for some activity or as an output resource resulting from some activity. Knowledge is traditionally categorized to tacit and explicit knowledge. Unlike explicit knowledge, tacit knowledge is hard to codify and it is tied to individuals. Knowledge is also tied to how individuals operate as a whole. In an innovative organization people work together to create something new: from a managerial perspective, the question is how to manage that individual knowledge efficiently in projects in order to satisfy customer needs (Lehtimaki ,Simula and Salo, 2009).

Tseng (2008) notes that due to knowledge is a more nebulous resource than data and information, tacit knowledge cannot be converted into explicit knowledge. As a result, people cannot articulate what they know. The implication is that knowledge can never be effectively shared through IT that involves a static repository-such as an intranet-because as static information, such knowledge can never convey the richness of the context in which it was applied.

Similar distinctions between explicit and largely tacit knowledge in organizations have been made. Explicit knowledge is the knowledge that can be easily captured artificially through manuals and standard operations, and then shared with others either through though courses or through books for self-reading. In an organization, tangible knowledge takes the form of job procedures as well as the company's philosophy and strategy (Lee\&Yang, 2000).

\section{KNOWLEDGE MANAGEMENT}

Tong and Mitra (2009) recognize KM as explicit control and management of knowledge within an Organization aimed at achieving the company's objectives. Though every organization holds knowledge, its benefits are only consistently realized if it is explicitly managed. A common challenge faced by most organizations is improving upon relative low productivity through explicitly managing existing knowledge. It Extracts the essence of Plato's original definition of knowledge and Treats it as "Justified true belief ", the debates surrounding this definition have been the driving force of many researchers' work .However, it is widely agreed that "knowledge"can be split along different dimensions. Existing knowledge classifications schemas within organization studies more or less build on the premise that distinguishes between tacit and explicit knowledge. Tacit knowledge is more subjective and experience based, consequently cannot be expressed easily. It always includes 
cognitive skills and technical skills. Explicit knowledge, on the other hand, is more rational knowledge that can be easily captured and communicated.

For a number of years now companies have focused on their knowledge resources as a primary means of gaining a strategic advantage. This focus has taken the form of an increased emphasis on knowledge management .The benefits of a well-functioning knowledge management system have been widely documented. Some of the more commonly noted benefits are: improved loyalty; speedier decision making; quicker "gearing-up" of staff; greater staff retention; development of more innovative ideas; greater flexibility in dealing with change and responding to crisis; increased capability to control the coordination of complex activities; and superior strategic decision making although the benefits described refer specifically to those experienced by organizations operating in an average business environment, they could be the types of benefits sought by an organization operating in a closed information environment. However, the benefits that have been identified as specifically applying to the latter types of organizations area reduction in time spent piecing together fragmented information which results in increased efficiency and effectiveness in solving complex problems; justification of research and development; and appropriate design of field operations and training programs ( Goh and Hooper, 2009).

Leverage knowledge as sets and create added value. KM see the knowledge available to accompany as a major success factor. It emphasized that KM addresses the issues of creating, capturing, and transferring knowledgebased sources. Both CRM and KM approaches can have a positive impact on reducing cost and increasing revenue. Knowledge is defined as information that is relevant, actionable, and based at least partially on experience in a business context. It is an emerging field that has commanded attention and support from the industrial community. Many organizations currently engage in knowledge management in order to leverage knowledge both within their organization and externally with shareholders and customers. A number of individuals and organizations have developed frameworks for knowledge management. In essence, they prescribe different ways to engage in knowledge management activities. A KM strategy can help tear down traditional cross-functional boundaries. KM entails helping people share and put knowledge into action by creating access, context, infrastructure, and simultaneously reducing learning cycles (Lin, Su and Chien, 2006).

Knowledge Management is the most appropriate management method and pattern for organizations (arabi, S. M., Mosavi, S., 2009). Due to the IT revolution and advancements of the Internet, the value of knowledge assets has been greatly enhanced. Many companies are building knowledge management system (KMS) in order to manage organizational learning and business know-how. The main purpose of such a policy is to help knowledge workers to create important business knowledge, to organize it, and to make it available when ever and where verities needed in the companies. Facing a tremendous amount of data on a daily basis, enterprises only use IT to integrate each division of various tools, such as intranet, data warehouse, electronic whiteboard, artificial intelligence and expert systems so that the jumbled business data is well-organized and more integrated. Furthermore, the value of business can be increased by applying IT (KM). The highest value of IT to KM is in allowing the expansion and universalization of the scope of knowledge and in increasing the speed of transferability. Additionally using IT, we are able to retrieve and store knowledge in individual or groups, which allows this knowledge to be shared with other divisions in the same organization or business partners in the world. Furthermore, IT contributes to the integration of knowledge or even to the stimulation of new knowledge. Nowadays, along lasting competitive advantage is achievable only if companies develop in to knowledge-creating companies. However, many companies have faced various kinds of difficulties in implementing KMS. First, if knowledge is merely accumulated in workers' brains, there is no way of recording it systematically. Second, even though knowledge is recorded and recorded in documents, it is very complicated to search for, retrieve, or review it, a problem which erects barriers to the discussion of knowledge. Thus, in past times, even though managers knew how important KM was, it was very difficult to implement it successfully (Tseng, 2008).

Knowledge, defined as information combined with experience, context, interpretation and reflection, can be divided in to explicit knowledge and tacit knowledge. Specifically, customer knowledge can also be classified as knowledge 'for', 'about' or 'from' the customer. KM is the explicit and systematic management of vital knowledge and its associated processes of creation, organization, diffusion, use and exploitation and CKM is the external perspective of KM (Nicolas and Castillo, 2008). The main purpose of KM is making information out of data, then making knowledge out of information (Zaferanian, R., et al, 2008). 


\section{CUSTOMER KNOWLEDGE MANAGEMENT}

With respect to the above issue, several discussions about its two related managerial aspects, Customer Relationship Management (CRM) and Knowledge Management (KM), can be found in the literature for CRM and KM. Thereafter, based on these discussions, many researches that expand on CRM/KM for promoting further customer relationships by effective management of customer knowledge have also been presented in recent years, which result in the concept of the so-called Customer Knowledge Management (CKM). In contrast to CRM/KM that addresses on providing customers with desired behaviors based on knowledge about these customers (e.g., their characteristics and preferences prevalent in previous work), CKM focuses on providing customers with desired(knowledge-accessed) behaviors that allow them to access knowledge from themselves (e.g., knowledge resident in themselves). As studied in with two dozens of enterprises that manage customer knowledge, CKM could make an enterprise much easier to fulfill/ expand its value creation process by seeking and leveraging customer knowledge through direct interaction with customers. Therefore, in our opinion, CKM would play a more contributive role than CRM/KM does in the success of Customer-Oriented EC (Lin, 2007).

Knowledge management and customer relation management (CRM) both emphasize on finding resources for supporting commercial processes of a firm. CRM sees the past, present and future customers as the success factor of the organization. Therefore, combining the two theories, CRM and KM, which is named CKM is a reasonable approach for achieving knowledge from customer and delivering the best and most appropriate knowledge to him (Akhavan, P., Heidary, S., 2008).

\section{SUPPLIER DEVELOPMENT}

Modi and Mabert (2007) mentioned Four useful supplier development strategies as follows:

1. Competitive pressure: Organizations make use of market forces to develop competitive pressure by using multiple sources .With the use of multiple suppliers to provide an item, an organization can distribute the volume of business such that the best performing supplier gets higher volume of business. This motivates other suppliers to improve quality, while maintaining pressure on the primary supplier not to let performance deteriorate. Suppliers demonstrating improved performance may be rewarded with increased business over time.

2. Evaluation and certification systems: The perceptions of the organization and its suppliers regarding the current and expected performance affect the performance of the supply chain. Routine supplier evaluation and feedback ensures that suppliers are aware of their performance and the customer organization's expectation of performance. Firms use formal supplier evaluation systems and supplier certification programs to communicate their expectations, plus motivate suppliers to improve performance.

3. Incentives: To motivate suppliers, an organization can also offer incentives. They include the sharing of achieved cost savings, giving consideration for increased volumes, future business, and recognizing supplier improvements through awards.

4. Direct involvement: Organizations take a proactive approach to developing suppliers through direct involvement .It is important to recognize that 'direct involvement' can be in a number of ways.(a) Procuring firms can make capital and equipment investments in supplier operations, like an investment in dies and fixtures. (b) Manufacturers can partially acquire the supplier firm. For example, manufacturers such as Toyota and Nissan typically have a $20-50 \%$ equity position in their largest suppliers. Such direct involvement involves huge financial investments by the procuring firm. (c) Firms may choose to invest human and organizational resources to develop supplier performance. It is the investment of human and organizational resources to develop supplier performance which is the focus of this research and is referred to as 'operational knowledge transfer activities'(OKTA).

\section{SUPPLIER KNOWLEDGE MANAGEMENT}

The buyer-supplier relationship is a key factor in manufacturing strategy when the environment is uncertain and dynamic. In the mid 1980s, transactions between buyers and sellers tended to rely on arms-length agreements based on market prices, while relationships in the 1990s were based more on trust derived from collaboration and information sharing. Hence, buyers used to play at a large number of suppliers against each other 
in order to gain price concessions and ensure continuity of supply at first, while only a small number of suppliers are required to supplement their core competences to satisfy their customers. The emergence and widespread use of the Internet allows these arch of suppliers from the smallest company to largest corporations on a global scale. This has resulted in the availability of a large number of qualified suppliers who can satisfy customers' requirements. The amount of supplier information grows exponentially and becomes almost a management nightmare. A lot of companies still rely on traditional IT systems to tackle problems at the data and information level but many errors have been reported to blame the supplier management system from the perspective of business intelligence. ( Choy, Lee, Lau and Choy ,2005).

The effective use of knowledge is a key component in every successful organization no matter what field or business function they may be in or what services the organization provides. Effective knowledge management enhances products, improves operational efficiency, speeds deployment, increases sales and profits, and creates customer satisfaction. But using knowledge correctly in an organization presupposes that management understands that the mere availability of disconnected or dispersed bits of information is not knowledge and that such bits can never adequately address these enterprise imperatives the KM market is highly competitive, and it has developed considerable uncertainty and risk because of the contradictory nature of its enabling technologies and the inherent organizational and cultural difficulties embedded in its applications. (Oppong \& Yen and Merhout, 2005).

\section{RESEARCH METHODOLOGY}

This paper is based on the review of the studies conducted in the area of Knowledge Management and Supplier Development. So after searching the two famous web-based journals archives, Emerald and Science Direct, for papers about "Knowledge Management" and Supplier Development ",several articles were found, among which some were selected that were close to the topic.

After that a conceptual model which was previously offered by Modi \& Mobert (2007), and its validity was tested and approved, is used to make a reasonable connection between the literature and the use of knowledge management in supplier development.

\section{CONCEPTUAL FRAMEWORK}

According to Modi and Mabert (2007), While past work suggests that an enterprise's supplier development programs involve important factors like supplier development strategies, communication and management involvement, it is useful to think about how they interact and ultimately influence performance. Fig. 1 provides a pictorial representation of how the four different supplier development strategies, collaborative communication, and bilateral top management involvement are linked.

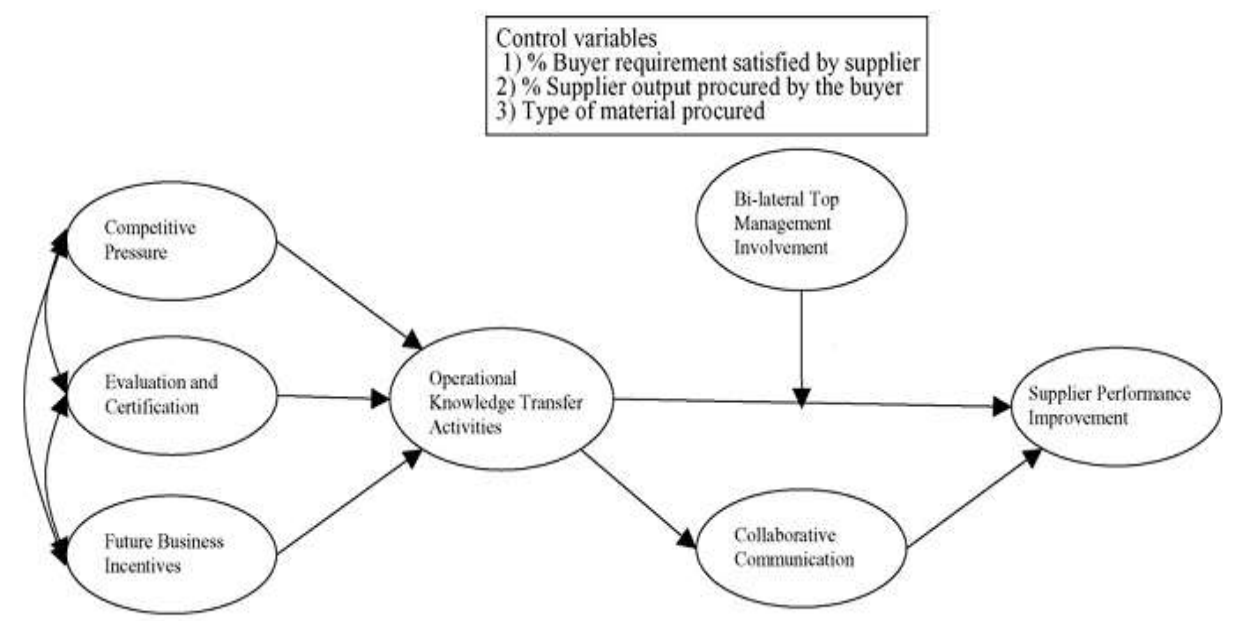

Fig. 1. Supplier development conceptual model. Paths from the control variables to all constructs are present but not shown in the figure.

Modi and Mabert (2007) 
8.1. Linking competitive pressure strategy and operational knowledge transfer activities: For extracting price benefits, firms can purposefully develop multiple suppliers for each product. Buyer-supplier relationships are normally arms-length or even adversarial. An adversarial approach to supplier relationships is a constraining factor in implementing joint activities requiring co-ordination between firms and their vendors. The use of multiple sources is representative of the use of market governance and an arms length relationship. On the other hand, developing suppliers by providing them with assistance, knowledge transfer efforts made by a firm involve intense commitment in terms of time and resources. Firm is typically target as mall number of suppliers for development. As firms try to rationalize their supply base and reduce the number of suppliers, they move towards fewer full service suppliers with the help of supplier development. This reduces the competitive pressure strategy with suppliers in this cooperative orientation environment.

8.2. Linking evaluation and certification to operational knowledge transfer activities: An evaluation of supplier's current performance provides information about the potential development requirements with the supplier, which in turn triggers supplier development activities. The literature on manufacturing capabilities also indicates that quality capability forms the basis for improvement in other capabilities such as dependable delivery, flexibility, and cost. As such, having some level of quality capability is imperative for development of other dimensions of performance. Therefore, firms will provide assistance to a select set of suppliers, using evaluation and certification to measure against qualification level before they further undertake activities to improve their performance. Evaluation and certification also provide organizations with a baseline for assessing the supplier's needed improvements. It is expected that firms will undertake the evaluation and certification activities prior to initiating operational knowledge transfer activities with the supplier.

8.3. Linking future business incentives to operational knowledge transfer activities: Procuring firms initiate knowledge transfer to suppliers and assist them in improving operations when the firms intend to have an ongoing supplier relationship. When organizations expect/desire to continue their relationship with the supplier, they can use it to motivate supplier through future business incentives prior to instituting direct involvement activities. Often, buying firms experience resistance from the supplier to open their facilities. Incentives motivate the supplier to open its facilities to the buying firm's staff and implement the operational improvements suggested by the procuring firm.

8.4. Linking operational knowledge transfer activities to performance improvements: As firms increase OKTA such as training of supplier personnel and "on-site" problem solving assistance, it helps the supplier's employees improve their skills and productivity. This increase in skill of the supplier will reflect in supplier's improved performance. OKTA like on site visits and problem solving assistance allow direct interaction between supplier and buyer personnel. Direct interaction at the individual level facilitates the demonstration and transfer of tacit knowledge. Interaction between the procuring firm's staff will empower the supplier personnel with the knowledge to tackle production problems and streamline their process for better performance and therefore OKTA are expected to lead to performance improvements of the supplier's operation.

8.5. Linking operational knowledge transfer activities to collaborative communication: A review of the past literature suggests that the link between collaborative communication and operational knowledge transfer activities, such as site visits and supplier training/education, has not been empirically tested. Ineffective communication can result from the use of unknown symbols, concepts and ideas, desire for secrecy, and a lack of motivation for information sharing. Direct contact and knowledge transfer between the buying and supplying firm staffs allow for a development of a common language. The initiation of knowledge transfer activities indicates a long-term relationship orientation on the part of the customer. Long-term relationship orientation increases communication between the firms. Such orientation leads to the establishment of trust between trading partners. Increased trust leads to a reduced desire for secrecy, motivating data sharing and facilitating greater collaborative communication. Involvement in OKTA indicates joint action on part of the involved firms requiring higher levels of co-ordination. As the level of joint activity increases, firms will share more information to effectively co-ordinate their operations and plans. Based on these arguments it is expected that OKTA will be positively associated with collaborative communication.

8.6. Linking collaborative communication to supplier performance improvements: The value of information exchange in supply chain relationships is well documented in the supply chain literature. Collaborative 
communication with suppliers benefits the buying firm in the long run, fostering an environment of mutual support and improving the responsiveness among supply chain partners. Greater information sharing between a firm and its suppliers can increase cost savings due to better operational efficiencies. While communication is necessary, increased communication canal so lead to information overload, having detrimental consequences. However, a lower level of communication can lead to conflicts that is detrimental to efficient co-ordination. Higher levels of collaborative communication in organizations leads to better co-ordination and effective completion of tasks, which positively affects the performance of alliance relationships. Supplier development activities represent a move towards an alliance relationship and similar effects can be expected on supplier performance improvements from collaborative communication.

\subsection{Role of bilateral top management involvement}

8.7.1. Linking operational knowledge transfer: Activities and bilateral top management involvement they note suppliers may be reluctant to participate in joint development activities that require suppliers to open their plants to the customer. As firms expand the level of knowledge transfer activities, the interdependence of the involved partners increases and facilitates greater data exchanges. Knowledge transfer activities involve joint action on part of the two firms. Increasing joint action "introduces more uncertainty into a firm's decision making because its activities are directly influenced by the other party's role performance". An organization's top management is aware of its current and future business needs. Bilateral top management involvement gives the customer and vendor the ability to align their objectives about their relationship and the efforts that are being made to improve the performance. Alignment of objectives will lead to lesser uncertainty in decision making as compared to situations where asymmetric objectives exist. In the presence of bilateral top management involvement, there will also be increased accountability of the customer's and vendor's development teams to reach the desired objectives for improvements. Such involvement can ensure that the financial resources required to implement the changes are available. Hence it is expected that the presence of bilateral top management involvement will lead to a more positive impact of OKTA on supplier performance improvement as compared to situations with lesser bilateral top management involvement.

\subsection{Control variables:}

Supplier development efforts are influenced by potential impact of the relationship. Three control variables were identified and added to the model. They are: (1) The percent of buyer requirement satisfied by the supplier. If a buyer procures a larger percent of their requirement from a supplier, they are more likely to use development strategies. They are also more likely to have better communication infrastructure and routines with such suppliers. (2) The percentage of supplier output bought by the buyer. If a buyer procures a large percentage of the supplier's output, the transaction represents an important customer. Hence, the supplier's motivation to improve its performance and meet buyer's criteria increases. (3) Type of material procured. It is possible that a buyer will make greater effort with suppliers who provide made-to-order products and these suppliers will show more improvement. While competitive pressure, evaluation and certification and future business incentives are often cited as important, the linkages/ interdependencies between are unclear. Firms may or may not use a combination of these strategies prior to implementing operational knowledge transfer activities with the supplier.

\section{CONCLUSION}

Nowadays, organizations not only should consider financial resources as their capital, but also should consider knowledge resources as assets. In the advanced countries economy, the balance between knowledge and other resources has changed in favor of knowledge, in a way that knowledge has become a determining component in life- even more important than land, work or wealth. Thus, lots of organizations are paying more and more attention to knowledge (Farhoodi,f., Daroodi,F., 2008).

Information and its effective use in decision making has caused the emergence of $\mathrm{KM}$. The core reasons leading to emergence of KM are: 1- The shift from the dominancy of tangible assets era to intellectual capital era, 2The dramatic increases in the volume of imformation, its electronic storage and increased access to information in general, and 3- The demographic changes accompanied with the danger of losing people through retirements. 
Initially, information technology departments were the focus of KM initiatives, however, as the focus moved to people's expertise, other departments became increasingly involved (Piri,Z., Asefzadeh, S., 2006).

A Knowledge Management System is a final product that includes several fields and links with organizational processes and uses various tools and techniques to achieve organizational goals.Recent studies present a potential challenge of knowledge management to gain competitive advantage. The main purpose of this paper was applying knowledge management tool to build an efficient and effective model for Supplier Knowledge Management system, through which organization would reach continous competitiveness. In SKM field, the outstanding idea is acquiring supplier's knowledge, then understanding and operating that knowledge.

For an enterprise, developing good relationship with suppliers is important to respond to rapid and uncertain environment changes. Hence, knowledge management supports business management to find, choose and keep reasonable supplier network in the best manner so that the firm can maintain its competitive advantages. The conceptual framework offered in this article, is a pictorial display of how knowledge management is used to facilitate supplier development.

Although it's a long period since the importance of Knowledge Management has been understood, few empirical studies have been conducted to investigate the relation between Knowledge Management strategies and organizational performance. Therefore further research in this area with an attention to the methods of quantifying the value of knowledge would be useful to understand the effects of implementing different KM systems.

\section{AUTHOR INFORMATION}

DR. Ali Mollahosseini, He has obtained PHD of management from Tehran University in 1998. Now he is associated professor of management in Shahid Bahonar university of Kerman, Iran .He has written 17 articles in the context of management in internal and external journals. Also, he has done 5 projects in different organizations .He has published two books. He has been consular in different organizations for 19 years and about 25 years teaching experience in different universities of Kerman, Iran.

Mehdi Barkhordar, He achieved his MBA from Bahonar University of Kerman in 2010. He has been lecturer since 2008 in Applied Sciences University of Kerman, Iran. He has published two articles in the management field and he has published one book. He has been working as a technical manager in a manufacturing company for three years.

\section{REFERENCES}

1. Akhavan, P.,Heidary, S., 2008.Customer Knowledge Management, an approach for achieving competing advantage. Future Management Journal 18, 24-40.

2. Arabi, S.M.,Mosavi, S., 2009. A Strategic Knowledge Management pattern for improving the performance of researching institutes. Research and Planning Journal in Higher Education 51, 1-26.

3. Campbell, A.J., 2003. Creating customer knowledge competence: managing customer relationship management programs strategically. Industrial Marketing Management 32, 375-383.

4. Choy, K.L., Lee, W.B., Lau, H.C.W., Choy, L.C., 2005.A knowledge-based supplier intelligence retrieval system for outsource manufacturing.Knowledge-Based Systems 18, 1-17.

5. Farhoodi,F., Darodi, F., 2008. Applying knowledge management essence in improving quality level of modern organizations activities.Sciences and IT 24(2), 89-107.

6. Gibbert, M., Leibold, M. Probst, G., 2002. Five Styles of Customer Knowledge Management, and How Smart Companies Use Them To Create Value. European Management Journal 20(5), 459-469.

7. Goh, C.H.T., Hooper,V., 2009. Knowledge and information sharing in a closed information environment. Journal of Knowledge Management 13(2), 21-34.

8. Hajiazizi, N., Dokhtesmati, M., Moradi, S., 25 Organizational amnesia: a modern approach in knowledge management. Iranian Scineces and Information Technology Institute Journal 25,2, 317-330.

9. Hall, R., Andriani, P., 1998. Management Focus:Analysing Intangible Resources and Managing Knowledge in a Supply Chain Context. European Management Journal 16(6), 685-697.

10. Lee, C.C., Yang, J., 2000. Knowledge value chain. Journal of Management Development 19(9), 783-793. 
11. Lehtimaki, T., Simula, H., Salo, J., 2009. Applying knowledge management to project marketing in a demanding technology transfer project: Convincing the industrial customer over the knowledge gap. Industrial Marketing Management 38, 228-236.

12. Lin, J., 2007. An object-oriented development method for Customer Knowledge Management Information Systems. Knowledge-Based Systems 20, 17-36.

13. Lin, Y., Su, H.Y., Chien, S., 2006. A knowledge-enabled procedure for customer relationship management. Industrial Marketing Management 35, 446-456.

14. Modi, S.B., Mabert, V.A., 2007.Supplier development: Improving supplier performance through knowledge transfer.Journal of Operations Management 25, 42-64.

15. Nicolas, C.L., Castillo, F.J.M., 2008. Customer Knowledge Management and E-commerce: The role of customer perceived risk. International Journal of Information Management 28, 102-113.

16. Olin, J.G., Greis, N.P., Kasarda, J.D., 1999.Knowledge Management Across Multi-tier Enterprises: The Promise of Intelligent Software in the Auto Industry. European Management Journal 17(4), 335-345.

17. Oppong, S.A., Yen, D.C., Merhout, J.W., 2005. A new strategy for harnessing knowledge management in e-commerce. Technology in Society 27, 413-435.

18. Piri, Z., Asefzade, S., 2006. How can we apply Knowledge management?. Ghazvin Medical University Journal 1, 124-132.

19. Salomann, H., Dous, M., Kolbe, L., Brenner, W., 2005. Rejuvenating Customer Management: How to Make Knowledge For,From and About Customers Work. European Management Journal 23(4), 392-403.

20. Shankar, R., Acharia, S. Baveja, A., 2009. Soft-system knowledge management Framework for new product development. Journal of Knowledge Management 13(1), 135-153.

21. Tong, J., Mitra, A., 2009. Chinese cultural influences on Knowledge Management practice. Journal of Knowledge Management 13(2), 49-62.

22. Tseng, S.M., 2008.The effects of information technology on knowledge management systems. Expert Systems with Applications 35, 150-160.

23. Wu, D.J., 2001. Software agents for knowledge management: coordinating in multi-agent supply chains and auctions. Expert Systems with Applications 20, 51-64.

24. Zafarian, R., Esmaeelzade, M., Shahi, N., 2008. Presenting an implementing model of knowledge management in small and medium businesses. Entrepreneurship development 2, 75-102. 
NOTES 